\title{
Fine Localization of Nefl and Nef3 and its Exclusion as Candidate Gene for Lens Rupture 2(Ir2)
}

\author{
Sang Dal RHEE2), Eunmin KIM3), Sungjoo Kim YOON3), Sung-Don YANG2), \\ Masaaki OKUMOTO4), Sang-Seop HAN 1), and Chang-Woo SONG1) \\ ${ }^{1)}$ Korea Institute of Toxicology, ${ }^{2}$ Korea Research Institute of Chemical Technology, 100 Jang-dong, \\ Yusong-gu, Taejon 305-343, ${ }^{3}$ Research Institute of Molecular Genetics, Catholic Research \\ Institutes of Medical Sciences, 505 Banpo-dong, Seocho-ku, Seoul 137-040, Korea, and \\ ${ }^{4)}$ Research Institute of Advanced Science and Technology, Osaka Prefecture University, \\ 1-1 Gakuen-cho, Sakai, Osaka, 599-8570, Japan
}

\begin{abstract}
Cataract causing Ir2 gene is found in the CXSD mouse, which is a recombinant inbred strain of BALB/C and STS mice. For the process of positional cloning of Ir2, several candidate genes were selected in the middle region of chromosome 14, but most of them were excluded by combination of recombination and homozygosity mapping. Components of neurofilament proteins, neurofilament light polypeptide (Nefl) and neurofilament3 medium (Nef3), were linked to D14Mit87 which was not separated from the Ir2 locus in the homozygosity mapping. When the expression levels of Nefl and Nef3 in eyes were compared in CXSD and BALB/C mice, there were no differences in expression levels. The CDNA sequences of the two genes from CXSD, BALB/C and STS mice were subsequently compared. Several nucleotide differences in CDNA sequences were detected between the mice strains but the majority of the changes were silent mutations that did not alter the amino acids. The sole amino acid difference, E567K in the glutamate rich region of $\mathrm{Nfm}$, between BALB/C and CXSD was found to be a simple genetic polymorphism because the same substitution existed in STS, a non-cataract mouse strain. Therefore we excluded Nefl and Nef3 from the candidate genes for Ir2 based on expression and mutation analyses.

Key words: cataract, exclusion, neurofilament genes, rupture
\end{abstract}

\section{Introduction}

Cataract is an opacity formation in the transparent lens, which may lead to blindness. A number of inherited cataracts are known in human and animals (Hejtmancik et al. 1998). So far, several model ani- mals of inherited cataract have been isolated (Iida $e t$ al. 1997). A recessive hereditary cataract mouse was discovered in the mouse strain, CXSD, which was one of the recombinant inbred (RI) strains derived from the mating of BALB/cHeA and STS/A mice (Hilgers and Arends 1985; Song et al. 1997a). The mutant gene has 
been named lens rupture 2 ( $\operatorname{lr} 2$, Mouse Gene Database accession number: MGD-JNUM-37399) because of the histological observation of posterior protrusion of lens materials accompanied by vacuoles in lens fiber. In CXSD mice, the first clinical symptoms of cataract appear at 5 weeks after birth and it seems to be completely penetrated. The $l r 2$ locus had been mapped to the middle region near D14Mit28 from the analysis of backcross mice (Song et al. 1997b). Subsequently, the $l r 2$ locus was finely mapped on the critical region of the $0.38 \mathrm{cM}$ interval in the middle region of Chr14. Several candidate genes were selected based on the previously reported maps (Dietrich et al. 1992 and 1996; Doolittle 1996) but were excluded by genetic or homozygosity mapping using the $\mathrm{F}_{2}$ mouse produced by intersubspecific mating between CXSD and Mus musculus molossinus (MSM) mice (Rhee et al. submitted).

In this report, we mapped Nefl and Nef3 and found that they are located in the critical region of the $\operatorname{lr} 2$ locus on mouse Chr 14, suggesting a strong possibility that they might be candidate genes for $\operatorname{lr} 2$. Thus the expression pattern and the sequences of the genes were analyzed to determine whether they are responsible for cataract formation in CXSD mouse.

\section{Materials and Methods}

Animals and Production of $F_{2}$ Mice: All mice were maintained in a barrier system under normal conditions of lighting (07:00-19:00 h), temperature $\left(24 \pm 0.5^{\circ} \mathrm{C}\right)$, relative humidity $(55 \pm 5 \%)$ and ventilation (10-12 times per hour). Mice were given filtered tap water $a d$ libitum in accordance with Guide for the Care and Use of Laboratory Animals (NIH). All animal experiments were carried out in accordance with the Guidelines for Animal Experimentation and with the permission of the Institutional Animal Care and Use Committee (IACUC of KRICT). CXSD mice, bearing the recessive cataract gene, have maintained for 43 generations by brother and sister mating in Osaka Prefecture University and the Korea Research Institute of Chemical Technology. MSM mouse was kindly provided by Drs. Miyashita and Moriwaki (National Institute of Genetics, Mishima, Japan). For genetic mapping, we generated intersubspecifically intercrossed progeny; that is, cataract CXSD mice were mated to MSM, and the (CXSD $\times \mathrm{MSM}) \mathrm{F}_{1}$ progeny were intercrossed $[(\mathrm{CXSD} \times$
$\left.\mathrm{MSM}_{2} \mathrm{~F}_{2}\right]$.

Genomic DNA Preparation, Polymerase Chain Reaction (PCR) and Mapping with Single Strand Conformational Polymorphism (SSCP) Analysis: Genomic DNA was isolated from the mouse tail by the procedure described elsewhere (Mori et al. 1995). Primers for mapping were derived from 3' UTR of the mouse cDNA sequences as shown in Table 1 . The polymerase chain reaction (PCR) was performed on $20 \mu$ reaction mixtures containing 1-10 ng template DNA, 1X Taq Buffer, $1.5 \mathrm{mM} \mathrm{MgCl} 2,200 \mu \mathrm{M}$ dNTPs, $0.2 \mu \mathrm{M}$ of each primer and $0.75 \mathrm{U}$ of Taq polymerase (PerkinElmer, Norwalk, CT, USA). PCR amplification was done with the following conditions using a thermocycler, model T-Gradient (Biometra, Goettingen, Germany): initial denaturation at $94^{\circ} \mathrm{C}$ for $2 \mathrm{~min}$; 35 cycles at $94^{\circ} \mathrm{C}$ for $30 \mathrm{~s}$, annealing for $30 \mathrm{~s}$, and $72^{\circ} \mathrm{C}$ for $1 \mathrm{~min} 30 \mathrm{~s}$; final extension at $72^{\circ} \mathrm{C}$ for $5 \mathrm{~min}$. Annealing temperatures are indicated in Table 1. The long PCR products were analyzed with the SSCP technique after digestion with a restriction enzyme, Hae III or Sau3A I. SSCP analysis was done by a slightly modified method of Spinardi et al. (1991). The PCR products or its digested products were denatured by boiling in buffer solution containing $95 \%$ formamide, $10 \mathrm{mM}$ EDTA, $5 \mathrm{mg} / \mathrm{m} l$ bromophenol blue and xylene cyanol. After cooling on ice, DNA fragments were separated by polyacrylamide gel electrophoresis with $4 \%$ stacking gel in $120 \mathrm{mM}$ Tris- $\mathrm{HCl}$ buffer $(\mathrm{pH} 7.3)$ and $8-15 \%$ running gel in $760 \mathrm{mM}$ Tris buffer $(\mathrm{pH} 8.2)$ with electrophoresis buffer of $12 \mathrm{mM}$ Tris, $96 \mathrm{mM}$ glycine, $\mathrm{pH} 8.5$ at constant temperature of $18^{\circ} \mathrm{C}$ for $4-5 \mathrm{~h}$, $15 \mathrm{~mA}$. DNA fragments were visualized by staining the gel with ethidium bromide or silver staining (Amersham Pharmacia Biotech, Uppsala, Sweden). The genetic locations of genes were mapped with the previously reported genetic recombination panel (Rhee et al., submitted).

RNA Isolation and cDNA Synthesis: Total RNA was extracted from the eye balls of 5 weeks old animals by guanidine hydrochloride lysis (Sigma, MO) and cDNA synthesis was carried out with a reverse transcription system (Takara, Japan).

Expression of Nefl and Nef3 in the Eyes: The expression levels of Nefl and Nef3 were analyzed with reverse transcription PCR (RT-PCR) methods. The PCR amplification conditions were initial denaturing at $94^{\circ} \mathrm{C}$ for 
Table 1. Primer sequences used in genetic mapping and mutant analysis of Nefl and Nef3

\begin{tabular}{|c|c|c|c|c|c|}
\hline Name & Forward primer & Reverse primer & $\begin{array}{l}\text { Anealing } \\
\text { Temp }\left({ }^{\circ} \mathrm{C}\right)\end{array}$ & $\begin{array}{l}\text { Product } \\
\text { size (bp) }\end{array}$ & Source \\
\hline \multicolumn{6}{|c|}{ For Mapping } \\
\hline Nefl & TCGCAAACATGTTGCCTGGAA & GCCTGTGCTTGTGCGGAGTA & 55 & 820 & GB:M55424 \\
\hline Nef3 & GGAGTCCGTTGCAAAAGGT & TTGCATGCAGTTCCCTCATA & 55 & 140 & GB:X05640 \\
\hline \multicolumn{6}{|c|}{ For Mutant Analysis } \\
\hline Nefl & & & & & GB:M20480 \\
\hline L1479 & GAGGAGGAGAGGAAAGAGGA & TTCGTGTTGTGTGTGTGGTTT & 55 & 540 & \\
\hline L1230 & ATTTTCACCAGCGTGGGTAG & CAACTGGTTGGTTGGTGATG & 55 & 500 & \\
\hline L954 & CTCCGCCTGCTCAAGGCTAA & GGGGCTCATCCTTGGCCTCCT & 60 & 490 & \\
\hline L695 & GAAGAAGGTGCACGAGGAAG & AAGCTGCAATCTCGATGTCC & 55 & 500 & \\
\hline L325 & ATCGCTTCGCCAGCTTCATC & TCGTACTGAGCGCGGATGTC & 55 & 500 & \\
\hline L20 & TGCAGTCACCATGAGTTCGT & AGCGCTTGCTTCTCGTTAGT & 55 & 490 & \\
\hline Nef3 & & & & & GB:X05640 \\
\hline M2192 & GAAGGAGAAGGCAGAGGAGG & TTGCATGCAGTTCCCTCATA & 55 & 600 & \\
\hline M1712 & TGAGAAGGAAGGCTCCAGTG & АСТСССТТССТССТСАСТGC & 55 & 500 & \\
\hline M1313 & ATTTTCAGGAAGCATCACCAG & GCATAGGGGATTTTGCTTTC & 55 & 600 & \\
\hline M903 & CAGACCAGAACATGCACCAG & GAGTTGGACCTTGAGCTTGG & 55 & 500 & \\
\hline M508 & TTACGACCAGGAGATCCGAG & CGATCTCTTCCTTGGCAGAG & 55 & 500 & \\
\hline M55 & GGCCTCCAAGATGAGCTACA & TCCTCCAAGTGATCGGAGTC & 55 & 550 & \\
\hline
\end{tabular}

Nefl, Neurofilment light polypeptide; Nef3, Neurofilament3 medium.

$15 \mathrm{~min}$, followed by 35 cycles consisting of $94^{\circ} \mathrm{C}$ for $30 \mathrm{~s}, 55^{\circ} \mathrm{C}$ for $30 \mathrm{~s}$ and $72^{\circ} \mathrm{C}$ for $1 \mathrm{~min}$, with a final extension at $72^{\circ} \mathrm{C}$ for $5 \mathrm{~min}$. Then the PCR products were analyzed with $1.5 \%$ agarose gel electrophoresis. The expression quantity was estimated by comparing the band density with that of housekeeping gene, GAPDH, using a densitometric computer program (ImageMaster Total Lab. Ver 1.0, Amersham Pharmacia Biotech., Uppsala, Sweden).

Sequence Analysis: The primers for obtaining cDNA sequences were derived from the reported sequences (GenBank: accession numbers listed in Table 1) and purchased from Bioneer Corp. (Cheongju, Korea). RTPCR products were cloned into $\mathrm{pCR} 2.1$ vector with a TA cloning kit from Invitrogen (Leek, the Netherlands) and both strands were sequenced using an ABI Prism System (Perkin-Elmer Corp. Calif. USA).

\section{Results}

We previously obtained the mapping panel from 10 mice bearing recombinations between D14Mit33 and D14Mit67. D14Mit28 and D14Mit87 were found to be located in the critical region with homozygosity map- ping (Rhee et al. submitted). The locations of several genes including $\mathrm{Nefl}$ and Nef3 that were previously mapped in the vicinity of the middle region of Chr. 14 were determined with SSLP and SSCP analysis. We were able to exclude most of these genes from the candidate genes. But Nefl and Nef3 were found to be closely linked with D14Mit87 that was not separated from the cataract phenotype in the homozygosity mapping (Fig. 1). In addition, Nefl and Nef3 were located in the same YAC clones in the physical map of the critical region (Rhee et al. submitted), thus suggesting these genes are strong candidates for $\operatorname{lr} 2$.

In order to investigate whether one of these genes is responsible for cataract in $\mathrm{CXSD}$, their mRNA expression levels in CXSD and BALB/c mice were compared. After total RNAs from the eyes of 5 weeks old mice of BALB/c and CXSD mice were obtained, the RT-PCR was used for analyzing whether mRNA expression levels of $N e f l$ or Nef3 were altered or not. The Nefl and Nef3 expression levels in eye of the CXSD mouse, however, were not different from that of the BALB/C mouse as shown in Fig. 2.

In order to analyze the sequences of $\mathrm{Nefl}$ and $\mathrm{Nef3}$, a series of cDNA fragments of all coding regions were 


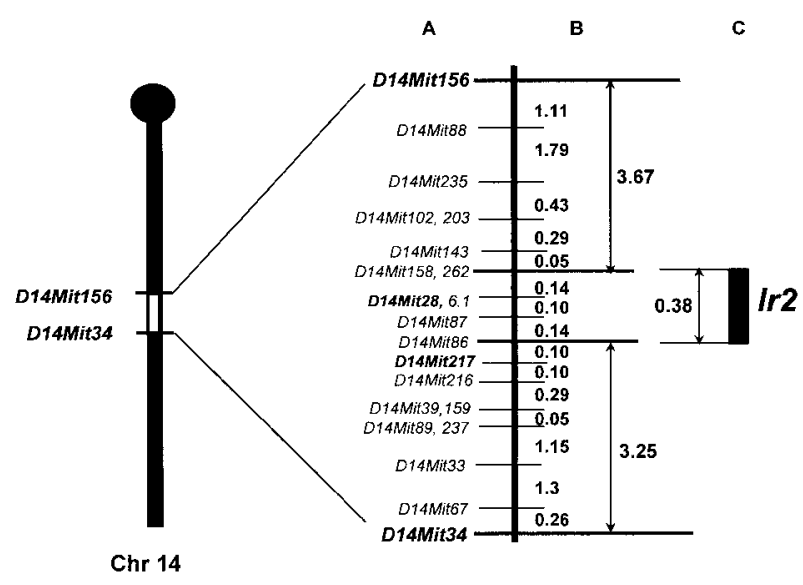

Fig. 1. Genetic mapping of $\mathrm{Nefl}$ and Nef3 by SSCP analysis. The mapping panel was composed from 10 recombinant $F_{2}$ mice produced by mating between CXSD and MSM mice. SSCP analysis was done by the method described in Materials and Methods. A Microsatellite markers and their map position; B distance between markers in centimorgan (cM); C lr2 locus base on homozygosity mapping and mating experiment.

\section{$\mathrm{BALB} / \mathrm{c}$}

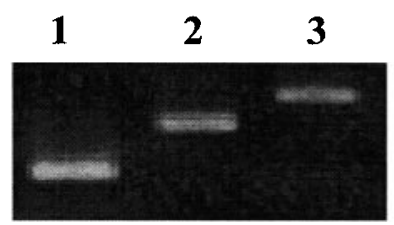

Fig. 2. mRNA expression patterns of $\mathrm{Nfl}$ and $\mathrm{Nfl}$ in the eyes of BALB/c and CXSD mice analyzed by RT-PCT. Lane 1, $\beta$-action; lane2, Nefl; lane3; Nef3.

obtained from strains of CXSD, BALB/c, and STS mice by RT-PCR, using primer sets derived from the previously reported sequences (GenBank accession numbers; M20480 for Nefl and X05640 for Nef3). All of the sequences were primarily compared with those cited in Genbank and with each other by BLAST. Nefl of the CXSD mouse has several nucleotide changes when compared to that cited in GenBank, but all nucleotide changes are silent and do not result in changes to the amino acid sequence. In the case of $\mathrm{Nef3}$, nucleotide changes were also observed at several positions of the sequence of GB dB: X05640, including a G to A transition at the nt4438 position of the cited sequence

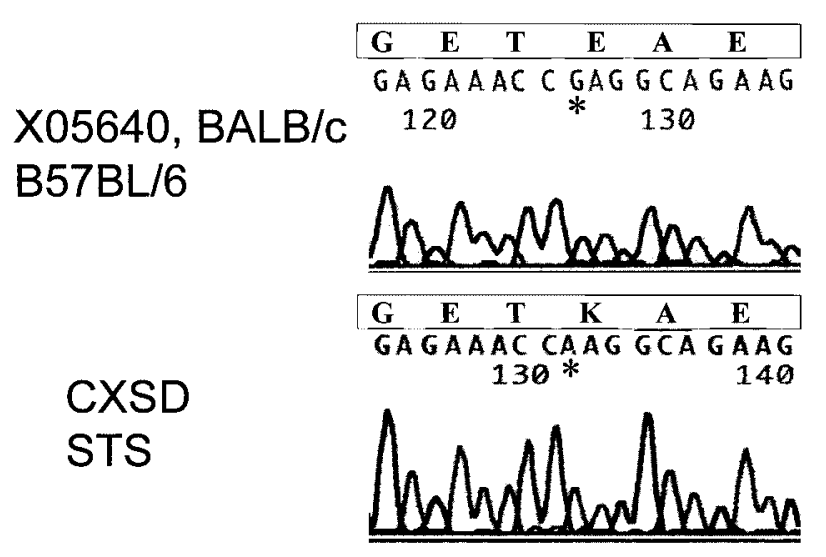

Fig. 3. Result of mutation analysis of Nef3 compared with the cited sequence of GenBank for CXSD, BALB/c and STS mice. $*$ indicates the position of nucleotide exchange in GenBank that resulted in an amino acid change, E567K.

resulting in a Glu567Lys amino acid change. The cDNA sequences from STS and BALB/c mice were subsequently analyzed to confirm the mutation. Only the G4438A change in the glutamate rich region of the carboxyl terminus of Nef3 was a real nucleotide change between CXSD and BALB/c (Fig. 3), but the nucleotide sequence of the CXSD mouse was the same as that of STS mouse which does not show the cataract phenotype. Thus, these data indicate that the G4438A mutation does not change the protein structure of Nef3 functionally, but is a simple genetic polymorphism between the mouse strains.

\section{Discussion}

Previously, we localized $l r 2$ gene to D14Mit28 on Chr. 14 using backcross progeny from the mating of STS and cataract CXSD mice, and by typing 5 polymorphic markers between D14Mit155 and D14Mit34 (about $7 \mathrm{cM}$ ) (Song et al. 1997b). The lr2 locus has been localized to a $0.38 \mathrm{cM}$ region using a combination of homozygosity mapping and additive mating with classical genetic mapping using intersubspecific mating between CXSD and MSM mice (Rhee et al. submitted). In addition to fine mapping of $l r 2$, we determined the position of several candidate genes of the cataract phenotype using genetic mapping as well as physical mapping. These genes include B lymphoid tyrosine kinase $(B l k)$, cathepsin B $(C t s b)$, A disintergrin and metalloprotease domain 7 (Adam 7$)$, clustrerin $(\mathrm{Clu})$, 
bone morphogenetic protein $1(\mathrm{Bmpl})$, a disintegrin and metalloprotease domain 2 (Adam2), protein tyrosine kinase $2 \mathrm{~b}(P t k 2 b)$, Nefl, Nef3, and gap junction protein 3 (Gja3). Blk, Ctsb, Clu, Bmpl, Adam 2 and Ptk2b were not present in the candidate region. Nefl, Nef3, Adam7 and Gnrh, which were not mapped in genetic mapping because of their non-polymorphism between MSM and CXSD mice, were found to be present in the YAC-STS physical map. Therefore, they have been subjected to further investigation.

$N e f l$ and Nef3 are the members of the intermediate filament (IF) protein composed of Nefl (61 kDa), Nef3 (90 kDa) and Nefh (110 kDa) (Julien 1997), and form the neurofilament by copolymerization. Neurofilaments are present in most populations of neurons in the nervous system to provide mechanical support to the neuron and play a role in modulating the caliber of large myelinate axons. Neurofilament deposit in degenerating motor neurons is related to diseases such as amyotrophic lateral sclerosis (ALS), and dramatic hypotrophy of axon was observed in the quivering quail mutant which is deficient in Nefl protein (Yamasaki et al. 1992), and in the Nefl knockout mouse (Julien 1999). The overexpression of $N e f l$ by murine sarcoma virus long terminal repeat promoter in the mouse led to cataract formation (Monteiro et al. 1990).

When Nefl and Nef3 were mapped with SSCP using the primers newly obtained from the 3' UTR of cDNA sequences of the genes, they were linked to D14Mit87 which was not separated from $1 r 2$ in the homozygosity mapping. Previous reports, that overexpression of Nefl is a cause of cataract (Monteiro et al. 1990), and that $\mathrm{Nefl}$ and $\mathrm{Nef3}$ are candidate genes of rupture of lens cataract $(r l c)$ which has similar phenotypes to $l r 2 \mathrm{mu}-$ tant (Matsushima et al. 1996), led us to suppose that these two genes were strong candidates for $l r 2$. Therefore, the expression level in the eyes and the cDNA sequence of $\mathrm{Nefl}$ and $\mathrm{Nef3}$ in several strains of mice were analyzed for mutations. The expression of $\mathrm{Nefl}$ and Nef3 in the eye was not different between BALB/c and CXSD mice. Several nucleotide changes were detected but most of them were silent mutations, which did not change the amino acid composition. Amino acid substitution was found at $\mathrm{E} 567 \mathrm{~K}$ in the sequence of Nef3, in which the acidic amino acid was changed to a basic amino acid, but this difference may not be a cataract causing mutation because glutamate (E) was found in the amino acid sequence in the BALB/c mouse and lysine $(\mathrm{K})$ in STS and CXSD mice. It may be a simple genetic polymorphism between the mouse strains for two reasons: 1) STS mouse that has lysine at position 567 does not have cataract; 2) the segregation ratio of phenotypes and genotypes in Mendelian analysis of the cataract gene was not different between backcross matings of $(\mathrm{CXSD} \times \mathrm{BALB} / \mathrm{c}) \mathrm{F}_{1} \times \mathrm{CXSD}$ and $(\mathrm{CXSD}$ $\times \mathrm{STS}) \mathrm{F}_{1} \times \mathrm{CXSD}$ in a previous report (Song et al. 1997), which showed that the genetic background of the STS mouse did not influence the cataract formation. The single amino acid change from acidic amino acid to basic amino acid buried in the long glutamate rich domain may not induce sufficient conformational change in the structure of Nef3 to induce cataract formation in the STS mouse. Thus we excluded the two neurofilament genes from the candidate genes for $l r 2$.

To date, there have been many genes reported to cause cataract. The several crystallins responsible for the maintenance of lens transparency (Stephan et al. 1999; Pras et al. 2000; Smith et al. 2000), transcription factors having important roles in the developmental process of the eye (Francis 1999), such as SOX1 (Nishiguchi et al. 1998), PITX3 (Semina et al. 1998), SIX5 (Sarkar et al. 2000) and PAX6 (Azuma et al. 1999), and the various proteins maintaining the intracellular environment including the gap-junction proteins such as Gja8 (Shiels et al. 1998; Steel et al. 1998) and Gja3 (Gong et al. 1997; Mackay et al. 1999) and Lferritin gene (Beaumont et al. 1995) have been related to cataract formation. In addition, a mutation in the cytoskeletal protein was also found as a minor mutation of cataract (Jakobs et al. 2000). Most of the genes reported so far are responsible for the cataract with autosomal dominant inheritance. The phenotype of $l r 2$ mice is distinct from others in that the lenses of mice affected appear clear at birth, but with time focal opacities develop, and the lenses eventually rupture. The progressive nature of the cataract with rupture may be suggestive of a gene developmentally regulated and involved in the cellular structure, but with a mechanism distinctive from other cataract mutants. Certain mutations in Nefl and Nef3 might be linked to the lens rupture because they maintain the cellular structure, but the critical mutations were not detected in this study, which suggests that $\operatorname{lr} 2$ might be a novel gene. 


\section{Acknowledgments}

This work was partially supported by grants Critical Technology 21(01-J-LF-01-B-72), National Research Laboratory (2000-N-NL-01-C-207) and Molecular Medicine Research Group Program (2000-J-MM-01-B01) from the Ministry of Science and Technology.

\section{References}

1. Azuma, N., Yamaguchi, Y., Handa, H., Hayakawa, M., Kanai, A., and Yamada, M. 1999. Missense mutation in the alternative splice region of the PAX6 gene in eye anomalies. Am. J. Hum. Genet. 65: 656-663.

2. Beaumont, C., Leneuve, P., Devaux, I., Scoazec, J.Y., Berthier, M., Loiseau, M.N., Grandchamp, B., and Bonneau, D. 1995. Mutation in the iron responsive element of the $\mathrm{L}$ ferritin mRNA in a family with dominant hyperferritinaemia and cataract. Nat. Genet. 11: 444-446.

3. Dietrich, W., Katz, H., Lincoln, S.E., Shin, H.-S., Friedman, J., Dracopoli, N.C., and Lander, E. S. 1992. A genetic map of the mouse suitable for typing interspecific crosses. Genetics 131: 423-447.

4. Dietrich, W.F., Miller, J., Steen, R., Merchant, M.A., Damron-Boles, D., Husain, Z., Dredge, R., Daly, M.J., Ingalls, K.A., O'Connor, T.J., Evans, C.A., DeAngelis, M.M., Levinson, D.M., Kruglyak, L., Goodman, N., Copeland, N.G., Jenkins, N.A., Hawkins, T.L., Stein, L., Page, D.C., and Landerm, E.S. 1996. A comprehensive genetic map of the mouse genome. Nature 380: 149-152.

5. Doolittle, D.P., Davisson, M.T., Guidi, J.N., and Green, M.C. 1996. Catalog of mutant genes and polymorphic loci. pp. 17-854. In: Genetic variants and strains of the laboratory mouse (3rd ed Lyon M.F., Rastan, S., Brown, S. D. M. eds.), Oxford University Press, London/New York.

6. Francis, P.J., Berry, V., Moore, A.T., and Bhattacharya, S. 1999. Lens biology: development and human cataractogenesis. Trends Genet. 15: 191-196.

7. Gong, X., Agopian, K., Kumar, N.M., and Gilula, N.B. 1999. Genetic factors influence cataract formation in alpha 3 connexin knockout mice. Dev. Genet. 24: 27-32.

8. Hejtmancik, J.F. 1998. The genetics of cataract: our vision becomes clearer. Am. J. Hum. Genet. 62: 520-525.

9. Hilgers, J. and Arends, J. 1985. A series of recombinant inbred strains between the BALB/cHeA and STS/A mouse strains. Curr. Top. Microbiol. Immunol. 122: 31-37.

10. Hoffman, P.N. and Lasek, R.J. 1975. The slow component of axonal transport. Identification of major structural polypeptides of the axon and their generality among mammalian neurons. J. Cell Biol. 66: 351-366.

11. Iida, F., Matsushima, Y., Hiai, H., Uga, S., and Honda, Y. 1997. Rupture of lens cataract: A novel hereditary recessive cataract model in the mice. Exp. Eye Res. 64: 107-113.

12. Jakobs, P.M., Hess, J.F., FitzGerald, P.G., Kramer, P., Weleber, R.G., and Litt, M. 2000. Autosomal-dominant congenital cataract associated with a deletion mutation in the human beaded filament protein gene BFSP2. Am. $J$. Hum. Genet. 66: 1432-1436.

13. Julien, J.P. 1997. Neurofilaments and motor neuron disease. Trends Cell Biol. 7: 243-249.

14. Julien, J.P. 1999. Neurofilament functions in health and disease. Curr. Opin. Neurobiol. 9: 554-560.

15. Klopp, N., Favor, J., Loster, J., Lutz, R.B., NeuhauserKlaus, A., Prescott, A., Pretsch, W., Quinlan, R.A., Sandilands, A., Vrensen, G.F., and Graw, J. 1998. Three murine cataract mutants (Cat2) are defective in different gamma-crystallin genes. Genomics 52: 152-158.

16. Mackay, D., Ionides, A., Kibar, Z., Rouleau, G., Berry, V., Moore, A., Shiels, A., and Bhattacharya, S. 1999. Connexin46 mutations in autosomal dominant congenital cataract. Am. J. Hum. Genet. 64: 1357-1364.

17. Matsushima, Y., Kamoto, T., Iida, F., Abujiang, P., Honda, Y., and Hiai, H. 1996. Mapping of rupture of lens cataract (rlc) on Mouse chromosome 14. Genomics 36: 553-554.

18. Monteiro, M.J., Hoffman, P.N., Gearhart, J.D., and Cleveland, D.W. 1990. Expression of NF-L in both Neuronal and Nonneuronal Cells of Transgenic Mice: Increased Neurofilament Density in Axon without Affecting Caliber. J. Cell Biol. 111: 1543-1557.

19. Mori, N., Okumoto, M., van Der Valk, M.A., Imaim, S., Hagam, S., Esakim, K., Hart, A.A.M., and Demant, P. 1995. Genetic dissection of susceptibility to radiation-induced apoptosis of thymocytes and mapping of Rapopl, a novel susceptibility gene. Genomics 25: 609-614.

20. Nishiguchi, S., Wood, H., Kondoh, H., Lovell-Badge, R., and Episkopou, V. 1998. Sox1 directly regulates the gamma-crystallin genes and is essential for lens development in mice. Genes Dev. 12: 776-781.

21. Pras, E., Frydman, M., Levy-Nissenbaum, E., Bakhan, T., Raz, J., Assia, E.I., Goldman, B., and Pras, E. 2000. A nonsense mutation (W9X) in CRYAA causes autosomal recessive cataract in an inbred Jewish Persian family. Invest. Ophthalmol. Vis. Sci. 41: 3511-3515.

22. Rhee, S. D., Kim-Yoon, S., Park, Y.-G., Lee, H., Yang, S.D., Okumoto, M., Esaki, K., Song, C-W., and Han., S.-S. 2003. Fine localization of the new recessive cataract gene (lr2) on mouse chromosome14: exclusion of several candidate genes(submitted).

23. Sarkar, P.S., Appukuttan, B., Han, J., Ito, Y., Ai, C., Tsai, W., Chai, Y., Stout, J.T., and Reddy, S. 2000. Heterozygous loss of Six 5 in mice is sufficient to cause ocular cataracts. Nat. Genet. 25: 110-114.

24. Semina, E.V., Ferrell, R.E., Mintz-Hittner, H.A., Bitoun, P., Alward, W.L., Reiter, R.S., Funkhauser, C., DaackHirsch, S., and Murray, J.C. 1998. A novel homeobox gene PITX3 is mutated in families with autosomal-dominant cataracts and ASMD. Nat. Genet. 19: 167-170.

25. Shiels, A., Mackay, D., Ionides, A., Berry, V., Moore, A., and Bhattacharya, S. 1998. A missense mutation in the human connexin50 gene (GJA8) underlies autosomal dominant "zonular pulverulent" cataract, on chromosome 1q. Am. J. Hum. Genet. 62: 526-532.

26. Smith, R.S., Hawes, N.L., Chang, B., Roderick, T.H., Akeson, E.C., Heckenlively, J.R., Gong, X., Wang, X., 
and Davisson, M.T. 2000. Lop12, a mutation in mouse Crygd causing lens opacity similar to human Coppock cataract. Genomics 63: 314-320.

27. Song, C.-W., Okumoto, M., Mori, N., Kim, J.-S., Han, S.S., and Esaki, K. 1997. Mapping of new recessive cataract gene (lr2) in the mouse. Mamm. Genome 8: 927-931.

28. Song, C.-W., Okumoto, M., Mori, N., Yamate, J., Sakuma, S., Kim, J.-S., Han, S.-S., Hilgers, J., and Esaki, K. 1997. A new hereditary cataract mouse with lens rupture. $L a b$. Anim. 31: 248-253.

29. Spinardi, L., Mazars, R., and Theillet, C. 1991. Protocols for an improved detection of point mutations by SSCP. Nucleic Acids Res. 19: 4009.

30. Steele, E.C. Jr., Lyon, M.F., Favor, J., Guillot, P.V., Boyd,
Y., and Church, R.L. 1998. A mutation in the connexin 50 (Cx50) gene is a candidate for the No2 mouse cataract. Curr. Eye Res. 17: 883-889.

31. Stephan, D.A., Gillanders, E., Vanderveen, D., Freas-Lutz, D., Wistow, G., Baxevanis, A.D., Robbins, C.M., VanAuken, A., Quesenberry, M.I., Bailey-Wilson, J., Juo, S.H., Trent, J.M., Smith, L., and Brownstein, M.J. 1999. Progressive juvenile-onset punctate cataracts caused by mutation of the gammaD-crystallin gene. Proc. Natl. Acad. Sci. U.S.A. 96: 1008-1012.

32. Yamasaki, H., Bennett, G.S., Itakura, C., and Mizutani, M. 1992. Defective expression of neurofilament protein subunits in hereditary hypotrophic axonopathy of quail. Lab. Invest. 66: 734-743. 